\title{
Practitioner Review: Short-term and working memory impairments in neurodevelopmental disorders: diagnosis and remedial support
}

\author{
Susan E. Gathercole and Tracy Packiam Alloway \\ University of Durham, UK
}

\begin{abstract}
Background: This article provides an introduction to current models of working and short-term memory, their links with learning, and diagnosis of impairments. The memory impairments associated with a range of neurodevelopmental disorders (Down's syndrome, Williams syndrome, Specific Language Impairment, and attentional deficits) are discussed. Methods: Methods of alleviating the adverse consequences of working and short-term memory impairments for learning are identified. Conclusion: Impairments of short-term and working memory are associated with learning difficulties that can be substantial, and that can be minimised by appropriate methods of remedial support. Keywords: Working memory, short-term memory, Down syndrome, Williams syndrome, Specific Language Impairment, attentional deficits.
\end{abstract}

Short-term and working memory are temporary memory systems that play important roles in supporting learning during the childhood years. The purpose of this review is to summarise current theoretical understanding of both working memory and short-term memory, to characterise short-term and working memory skills impairments associated with a range of neurodevelopmental disorders, and to identify methods of remedial support appropriate for children with these impairments.

\section{Working memory, short-term memory, and learning}

The key feature of working memory is its capacity both to store and manipulate information. Working memory functions as a mental workspace that can be flexibly used to support everyday cognitive activities that require both processing and storage such as, for example, mental arithmetic. However, the capacity of working memory is limited, and the imposition of either excess storage or processing demands in the course of an ongoing cognitive activity will lead to catastrophic loss of information from this temporary memory system.

An individual's working memory capacity is usually assessed using complex memory span tasks in which the participant is required to process and store increasing amounts of information until the point at which recall errors are made. The first complex memory span task, reading span, was developed by Daneman and Carpenter (1980). In reading span, the individual reads a series of sentences, and finally attempts to recall the final word of each sentence in order. A processing task such as reading the sentence aloud or judging its veracity ensures that each sentence is processed. Other variants of the complex memory span paradigm include listening span (in which the sentences are presented auditorily; Daneman \& Carpenter, 1980), counting span (in which the task is to count the number of target objects in each of a series of displays and subsequently recall their tally numbers; Case, Kurland, \& Goldberg, 1982), and operation span (in which participants perform mathematical calculations and finally attempt to recall unrelated items presented immediately after each solution; Turner \& Engle, 1989).

The functional capacity of working memory measured via complex memory span tasks varies markedly across both individuals and age, particularly during the childhood years (see, e.g., Gathercole, Alloway, Willis, \& Adams, 2004a). Performance improves steadily until the teenage years, when it starts levelling off. By the age of 15, levels close to those of adults are reached. At any particular age, the degree of variation in working memory capacity is sizeable, spanning many years of average development.

The key finding from the Daneman and Carpenter (1980) study was that measures of verbal complex memory span measures were strongly associated with a range of measures of learning ability. High correlations were found between reading span and college students' performance both on verbal Scholastic Aptitude Tests and on measures of reading comprehension, suggesting that working memory capacity has important consequences for high cognitive function. What distinguishes these complex memory span tasks from other measures of cognitive abilities such as IQ is that performance is not limited by the difficulty of the processing activities per se, as these can be performed accurately in isolation. Instead, the crucial limiting factor is the sheer amount of information that can be processed and stored at the same time. 
During childhood, associations between working memory capacity and attainments are similarly high. Scores on verbal complex memory span measures are highly predictive of a wide range of measures of academic ability, including literacy (e.g., De Jong, 1998; Gathercole \& Pickering, 2000; Gathercole, Pickering, Knight, \& Stegmann, 2004b; Swanson, 1994), mathematics (e.g., Bull \& Scerif, 2001; Gathercole \& Pickering, 2000; Gathercole et al., 2004b; Mayringer \& Wimmer, 2000; Siegel \& Ryan, 1989), and language comprehension (e.g., Cain, Oakhill, \& Bryant, 2004; Nation, Adams, BowyerCrain, \& Snowling, 1999; Seigneuric, Ehrlich, Oakhill, \& Yuill, 2000). Complex memory span scores are strongly associated with teacher ratings of children's general abilities at school entry at 4 years of age (Alloway, Gathercole, Adams, \& Willis, in press), and are effective predictors of scholastic attainments over the subsequent school years (Gathercole, Brown, \& Pickering, 2003).

Perhaps most importantly, deficits of working memory are found in children with learning difficulties in literacy and mathematics (e.g., Gathercole \& Pickering, 2001; Geary, Hoard, Byrd-Craven, \& DeSoto, 2004; Siegel \& Ryan, 1989; Swanson, 1993) that are extremely rare in samples of children without learning difficulties (Pickering \& Gathercole, 2004). Our own recent findings indicate that impairments of working memory are more characteristic of children whose learning difficulties extend across the domains of literacy and mathematics than of those with difficulties restricted to literacy alone (Gathercole et al., 2004a; Pickering \& Gathercole, 2004). Verbal working memory skills do not appear to simply be a proxy for more general cognitive abilities: the relationship between verbal working memory skills and more general learning difficulties is not mediated by either verbal abilities or IQ (Gathercole et al., 2004a; see also, Cain et al., 2004).

Although most research has focused on verbal working memory, recent evidence indicates that there is a separate working memory capacity for visuo-spatial material that is also important for learning. In a study of 11- and 14-year-old children, we found that both verbal and visuo-spatial working memory scores each had strong and distinct links with children's attainments in national curriculum assessments (Jarvis \& Gathercole, 2003). Visuospatial memory scores were particularly strongly linked with performance in mathematics and science.

There are several models of working memory (e.g., Baddeley, 1996; Barrouillet, Bernardin, \& Camos, 2004; Case et al., 1982; Cowan, 2001; Engle, Kane, \& Tuholski, 1999; Just \& Carpenter, 1992). One common feature shared by the various models is that working memory is supported by a limited capacity resource that some theorists link with attention (e.g., Barrouillet et al., 2004; Cowan, 2001). Working memory is related to, but distinguishable from, short-term memory. Whereas working memory involves both the storage and processing of information, short-term memory systems are specialised purely for the temporary storage of material within particular informational domains.

For the purposes of this article, the theoretically neutral terms working memory and verbal short-term memory are used in preference to terms specific to particular theoretical models. It is, however, important to consider in some detail the most influential model of working memory, originating from Baddeley and Hitch (1974). According to recent versions of this model, the processing element of complex memory span tasks is supported by the central executive, a limited capacity system involved in regulatory control of working memory. The storage demands of verbal complex span tasks are met by a separate short-term memory system, the phonological loop (Baddeley \& Logie, 1999). The detailed structure of the current working memory model (Baddeley, 2000) is shown in Figure 1 .

The phonological loop component of the working memory model (Baddeley, 1986) consists of two components: a short-term store that maintains phonological representations and is subject to rapid delay, and a subvocal rehearsal process that acts to refresh decaying phonological representations in the store. Note that spontaneous use of rehearsal does not emerge typically until about 8 years of age (Gathercole \& Hitch, 1993). Any information that is verbalisable (such as spoken words, printed words, nameable objects) can be stored in the phonological loop. Like verbal working memory, the capacity of the phonological loop undergoes steady development from early childhood to early adolescence, levelling off towards 15 year of age.

The third component of the working memory model is the visuo-spatial sketchpad, a system specialised for temporary visuo-spatial storage (see, e.g., Logie, 1995). The final element of the model, the episodic buffer (Baddeley, 2000), is responsible for the integration of information from different components of both working memory and long-term memory in multi-dimensional representations.

The capacities of verbal and visuo-spatial shortterm memory vary widely between individuals, and

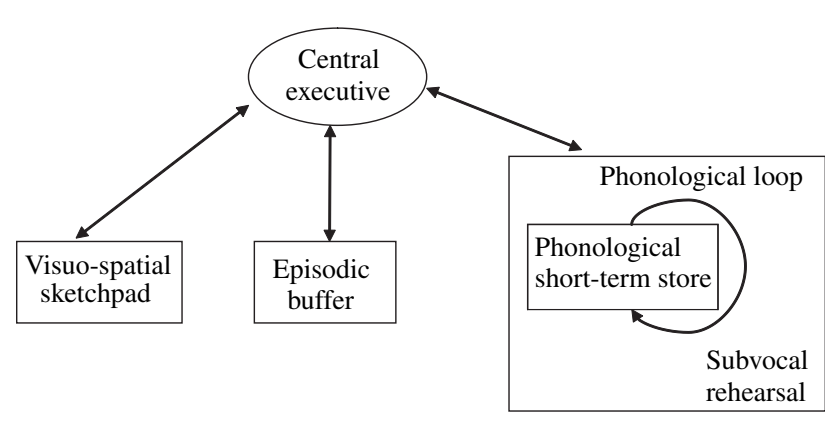

Figure 1 Current version of the working memory model, adapted from Baddeley (2000) 
independently from one another (e.g., Pickering, Gathercole, \& Peaker, 1998). Short-term memory skills are much more weakly associated with general academic and cognitive performance than working memory skills (e.g., Daneman \& Merikle, 1996). There is, however, a strong and highly specific link between verbal short-term memory and the learning of the sound patterns of new words in both the native language over the early childhood year, and in second language learning at all ages (e.g., Gathercole, Hitch, Service, \& Martin, 1997; Service \& Craik, 1993; Service \& Kohonen, 1995). Children with poor verbal memory skills have specific impairments in the process of learning the phonological structures of new vocabulary items, and so acquire new vocabulary items at a much slower rate than other children (for review, see Baddeley, Gathercole, \& Papagno, 1998). Developmental consequences of impairments of visuo-spatial short-term memory have not been established, and so will not be discussed further here.

Although the mechanisms underlying the link between impairments of working memory and learning difficulties are not as yet fully understood, recent evidence suggests that it arises from working memory constraints operating at the point of learning. In an observational study of young children with marked impairments of working memory, it was found that they made frequent errors in activities with heavy working memory demands such as remembering complex instructions, concurrent processing and storage demands, and keeping track in multi-level tasks such as writing (Gathercole, Lamont, \& Alloway, in press). We proposed that these failures to meet the working memory demands of classroom activities are a cause of their learning difficulties. In order to make good academic progress, the child has to succeed in many different structured learning activities designed to accumulate across time the body of knowledge and skills that they need in areas of the curriculum such as literacy and mathematics. If he or she frequently fails in individual learning situations due to an inability to store and manipulate information in working memory, the incremental progress towards the acquisition of complex knowledge and skills will be slow and difficult. In this way, working memory may act as a bottleneck for learning (Gathercole, 2004).

In summary, both working memory and verbal short-term memory contribute to learning during childhood years. Their contributions are quite distinct: working memory plays an important role in supporting the acquisition of complex skills and knowledge in academic areas such as literacy and mathematics, whereas verbal short-term memory is involved the learning of the sound structures of new words. Developmental impairments in either memory system have deleterious consequences for learning and academic progress in these domains.

\section{Diagnosis of impairments of short-term and working memory}

Recommendations for the diagnosis of impairments of short-term and working memory are summarised in Table 1. As a rule of thumb, scores more than one standard deviation below the mean (16th centile) are considered to represent mild impairments and scores more than 1.33 standard deviations below the mean (9th centile) represent moderate to severe impairment. Impairments of working memory should be identified independently of other aspects of a child's cognitive profile, and do not require the use of discrepancy criteria related to IQ. The reason for this is that working memory and IQ have separable links with learning, although they are typically positively related. In particular, children with low IQ scores tend to have more pervasive learning difficulties if they have also have moderate or severe impairments of working memory (Gathercole et al., 2004a). Assessment of working memory is therefore important even in individuals with low general intellectual function.

Impairments of working memory can be identified in either of two ways: by preliminary screening using

Table 1 Diagnosis of impairments of short-term and working memory: inclusionary and exclusionary criteria

\begin{tabular}{|c|c|c|c|c|}
\hline \multirow[b]{2}{*}{ Criteria } & \multicolumn{2}{|c|}{ Preliminary assessment } & \multicolumn{2}{|c|}{ Follow-up assessment } \\
\hline & Assessment & Criterion & Assessment & Criterion \\
\hline \multicolumn{5}{|l|}{ Inclusionary: } \\
\hline Verbal STM & $\begin{array}{l}\text { Forwards } \\
\quad \text { digit span }\end{array}$ & $>1 \mathrm{SD}$ below mean & $\begin{array}{l}\text { At least one further measure: } \\
\text { e.g., word recall, nonword recall }{ }^{1}\end{array}$ & $>1 \mathrm{SD}$ below mean \\
\hline Verbal WM & $\begin{array}{l}\text { Backwards } \\
\text { digit span }\end{array}$ & $>1 \mathrm{SD}$ below mean & $\begin{array}{l}\text { At least one further measure: } \\
\text { e.g., listening span, counting span }\end{array}$ & $>1 \mathrm{SD}$ below mean \\
\hline \multicolumn{5}{|l|}{ Exclusionary: } \\
\hline Hearing & Informal & $\begin{array}{l}\text { Appears to have } \\
\text { hearing difficulties }\end{array}$ & Standard audiology & Impaired \\
\hline Speech-motor & Informal & Poor pronunciation & Picture naming $^{2}$ & $\begin{array}{l}\text { Restricted phonological } \\
\text { system }\end{array}$ \\
\hline
\end{tabular}

\footnotetext{
${ }^{1}$ e.g., Working Memory Test Battery for Children, Pickering \& Gathercole (2001).
}

${ }^{2}$ e.g., Goldman-Fristoe Test of Articulation-2, Goldman \& Fristoe (2000). 
appropriate sub-tests of standardised ability tests followed by further appropriate memory tests if required, or by using a specialised working memory test battery. If the former approach is adopted, two measures included in many general ability tests can be used for initial screening purposes. Forwards digit span involves the auditory presentation of random digit sequences for immediate spoken recall, and yields a reasonable initial assessment of verbal short-term memory. However, as the processing load of this test is minimal, it does not tap working memory. The second memory test, backwards digit span, does provide a useful measure of working memory capacity. The requirement to recall the digits in reverse sequence imposes a substantial processing load on the child, necessitating the mental re-sequencing of the memory representation. It should be noted that in some test batteries (e.g., British Abilities Scales II, Elliot, Smith, \& McUlloch, 1996; and WISC-III, Wechsler, 1992), scores on forwards and backwards digit span are aggregated to yield a single memory score. Because the two measures assess separate memory systems as outlined in the previous section, these scores do not provide an adequate basis for distinguishing between impairments of verbal short-term memory and verbal working memory if they fall in the 'impaired' range. However, tables in the manuals of some standardised ability tests can be used to calculate whether there are significant differences between forwards and backwards digit span. The finding of a significant deficit across the two tests will provide an adequate basis for a preliminary diagnosis of an impairment of either verbal short-term or working memory.

Although forwards and backwards digit span provide acceptable preliminary estimates of verbal short-term and working memory respectively, these measures need to be supplemented by further assessment of the relevant memory system before a diagnosis of impairment is made. The most significant shortcoming of both measures is that they employ numerical stimuli, which can provide misleading results for children with number-based processing problems; they may perform poorly on the task as a consequence of their lack of facility with the stimuli rather than as a result of memory problems per se. It is also far from ideal to base a diagnosis of a specific memory deficit on a single measure administered on a single occasion.

There are a number of other suitable assessments of verbal short-term memory and working memory that can be used with children who perform poorly on either of the two digit span measures. One measure that is strongly associated with verbal short-term memory deficits is nonword repetition, in which the child attempts to repeat single multi-syllabic nonwords. Suitable standardised measures include the Children's Test of Nonword Repetition (Gathercole \& Baddeley, 1996) and Nonword
Repetition Task (Campbell, Dollaghan, Needleman, \& Janosky, 1997).

Multiple assessments of both verbal short-term and working memory are provided in two working memory test batteries standardised for children. The Working Memory Test Battery for Children (WMTBC; Pickering \& Gathercole, 2001) includes four measures of verbal short-term memory: digit recall, word recall, nonword recall, and word list matching recall. All four measures involve verbal presentation of memory items, with the first three tests requiring immediate spoken recall. Word list matching involves the child judging whether two spoken sequences are identical or not, as it places minimal demands on phonological and articulatory production skills. This test is particularly appropriate for use with children with speech-motor deficits. Scores on all four measures are used to derive a standardised verbal memory composite score. The WMTB-C also includes three measures of verbal working memory (listening recall, counting recall, and backwards digit recall), scores on which are used to derive a composite working memory score. Finally, the WMTB-C includes three measures of visuo-spatial short-term memory (matrices, mazes memory, and block recall). The Automated Working Memory Assessment (AWMA; Alloway, Gathercole, \& Pickering, 2004) is a computer-based assessment that provides three measures each of verbal short-term memory, visuo-spatial short-term memory, verbal working memory, and visuo-spatial working memory.

In diagnosing impairments of both verbal working memory and short-term memory, it is necessary to exclude potential non-memory causes of low test performance. One such factor is speech-motor dysfunction, which may give rise to inaccurate recall protocols on measures requiring verbal recall, particularly on test such as word recall, nonword recall, and nonword repetition that use open sets of stimuli of relatively low familiarity, and in which recall must be accurate at the phoneme level. If speech-motor problems are suspected, it is advisable to provide a systematic assessment of speech production using picture-based naming tests that sample the full range of phonological contrasts in the language (e.g., Goldman \& Fristoe, 2000). Errors made in memory assessments that correspond to systematic errors in phonological production should be disregarded.

Hearing impairments may also contribute to low test scores on measures of verbal short-term and working memory due to problems in the initial discrimination of memory items, particularly in tests involving unpredictable phonological sequences such as nonword repetition and nonword recall (Briscoe, Bishop, \& Norbury, 2001). As the precise profile of auditory processing deficits resulting from hearing impairments will depend on the severity and frequency range of the impairments as well as the specific acoustic contrasts sampled in the stimuli, it is difficult to predict the consequences of the 
impairments on test scores. For neurodevelopmental disorders commonly associated with hearing impairments such as Down syndrome and in any cases in which hearing is suspected, a full audiological assessment is recommended in order to identify whether hearing problems are a possible source of low memory test scores. For individuals with a confirmed hearing impairment, non-auditory methods of assessing memory, such as visual presentation of memory items in either printed word form or pictorial form in cases of assessments of the phonological loop, can be used. However, no such tests are as yet standardised for use with children. A further problem is that because non-auditory presentation formats such as these require subvocal rehearsal in order to generate phonological representation in verbal short-term memory, these methods are only suitable for children who are able to rehearse. Typically, spontaneous use of rehearsal emerges at about 8 years.

Finally, it is important to note that although working memory is often considered as a higher executive function associated with the engagement of the frontal lobes, impairments of working memory within both developmental and adult neuropsychology have been found to be largely independent of other classic executive functions such as shifting, planning, inhibition, and verbal fluency (e.g., Pennington \& Ozonoff, 1996). A child with an impairment of working memory would therefore not necessarily be expected to exhibit deficits in these other executive functions.

\section{Working memory and neurodevelopmental disorders}

In this section, memory profiles characteristic of four neurodevelopmental disorders are considered. In each case, the disorders are associated with impairments of either short-term or working memory. Issues related to diagnosis and remedial support that are specific to the disorders also raised.

\section{Down syndrome}

There is substantial evidence that individuals with Down syndrome have a marked deficit of verbal short-term memory that exceeds their general diffculties with language. Groups with Down syndrome have been consistently found to be impaired on measures of verbal short-term memory relative to control groups composed either of individuals with moderate learning difficulties of mixed aetiology, or of younger typically developing children matched for mental age (e.g., Broadley, MacDonald, \& Buckley, 1995; Jarrold, Baddeley, \& Hewes, 1999; Laws, 1998; Mackenzie \& Hulme, 1987). Their visuo-spatial short-term memory function, on the other hand, is typically appropriate for mental age.
The precise cause of the selective impairment of verbal short-term memory in Down syndrome is still not known. One possibility is that individuals with Down syndrome have a particular problem with subvocal rehearsal, which plays a crucial role in actively maintaining phonological representations in short-term memory and preventing them from rapid decay. Consistent with this view, groups with Down syndrome have been shown to benefit from training of an overt cumulative rehearsal strategy, in which participants are required to rehearse aloud increasing amounts of material in the course of a short-term memory task (Broadley \& MacDonald, 1993; Comblain, 1996; Laws, McDonald, \& Buckley, 1996). Another possibility is that the low verbal memory performance associated with Down syndrome reflects inadequacies in the storage of phonological material in short-term memory, for example in the quality of the phonological representations or in the rate of decay (e.g., Jarrold, Baddeley, \& Hewes, 2000; Jarrold, Baddeley, \& Phillips, 1999).

Because intact phonological loop function is important for long-term learning the sound structures of new words (Baddeley et al., 1998), it is likely that individuals with Down syndrome who have deficits of verbal short-term memory will be slower to acquire new vocabulary than would be expected on the basis of their general cognitive abilities. Additional focused support for vocabulary learning for such individuals may therefore be of particular value in enhancing their language development.

\section{Williams syndrome}

Williams syndrome (WS) is a much rarer genetic disorder than Down syndrome, present in approximately 1 in 50,000 live births. Individuals with Williams syndrome typically have severe deficits in aspects of spatial cognition including pattern construction, drawing and visual processing (e.g., Bellugi, Wang, \& Jernigan, 1994; Farran, Jarrold, \& Gathercole, 2001). In marked contrast, expressive language abilities in WS are much stronger, and can include excellent pragmatic use of language and good vocabulary knowledge (e.g., Bellugi et al., 1994).

Williams syndrome is associated with a substantial deficit of visuo-spatial short-term memory that mirrors the more general impairment of spatial cognition. Individuals with William syndrome typically show the converse profile of short-term memory function to those with Down syndrome, with much stronger verbal short-term memory than visuo-spatial memory skills (Wang \& Bellugi, 1994; Jarrold, Baddeley, Hewes, \& Phillips, 2001).

There is some evidence that visuo-spatial shortterm memory supports long-term learning within this modality, particularly in learning new spatial routes (Hanley, Young, \& Pearson, 1991). The very poor visuo-spatial memory skills of individuals with Williams syndrome may therefore be a contributor to 
their impaired visuo-spatial learning abilities. Structured support for learning important visuospatial information is recommended in order to compensate for their difficulties in this domain.

\section{Specific Language Impairment}

Specific Language Impairment (SLI) is a relatively common developmental language disorder, with an estimated incidence of around $7 \%$ of the population (Tomblin et al., 1997). It is characterised by delayed or disordered language development in the absence of general cognitive deficits, sensory disorders, or neurological damage. The condition has a strong genetic basis (Bishop, North, \& Donlan, 1996), and is associated with abnormalities at chromosomes 16 and 19 (SLI Consortium, 2002).

SLI is associated with impairments of both verbal short-term memory and working memory. A hallmark of SLI is that affected children have severe deficits in one measure associated with verbal shortterm memory that exceed even the criterial language impairments - nonword repetition (Dollaghan, \& Campbell, 1998; Edwards \& Lahey, 1998; Ellis Weismer et al., 2000; Gathercole \& Baddeley, 1990; Montgomery, 1995). This nonword repetition deficit is highly heritable (Bishop et al., 1996, 1999; SLI Consortium, 2002), and has been identified as a phenotypical marker of SLI (Bishop et al., 1996).

Because individuals with SLI have a constellation of language deficits, diagnosis of impairments of verbal short-term memory often requires consideration of non-memory factors. In particular, many children with SLI have deficits of output phonology and articulation, and some researchers believe that they also have subtle auditory processing problems (Tallal, Merzenich, Miller, \& Jenkins, 1998). In such cases, further testing following the procedures outlined in Table 1 is recommended.

It is now evident that children with SLI also have impairments of verbal working memory. They perform very poorly on measures of verbal complex memory (Ellis Weismer, Evans, \& Hesketh, 1999; Montgomery, 2000). In a recent study, we found that the deficits of a group of children with SLI in verbal working memory were even more marked and consistent than their impairments of verbal short-term memory, affecting every child in the group (Archibald $\&$ Gathercole, 2004).

Verbal working memory deficits may not necessarily be the underlying cause of SLI. The deficits are, however, likely to contribute to the substantial learning difficulties in core areas of the school curriculum such as literacy and mathematics that are characteristic of SLI (Catts, Fey, Tomblin, \& Zhang, 2002; Fazio, 1996). Effective management of working memory loads in order to reduce the impact of their impairments of working memory on general learning (see Remedial support section below) is therefore a priority in children with SLI.

\section{Attentional disorders}

Attentional Deficit with Hyperactivity Disorder (ADHD) is a relatively common developmental disorder, with an estimated rate of prevalence of between $1 \%$ and $7 \%$ (Hinshaw, 1994). It has a strong familial pattern, and is moderately heritable. The DSM-IV provides diagnostic criteria for two distinct behavioural dimensions characterised by inattention and hyperactive-impulsive behaviour; a combination of these behaviours is classified as an additional subtype of this disorder (see Barkley, 2003, for a review).

Individuals diagnosed with either predominately hyperactive-impulsive or combined type behaviours are characterised by impairments of executive functioning, particularly in tasks relating to inhibition or prepotent responses (Geurts, Vertie, Oosterlaan, Roeyers, \& Sergeant, 2004; Barkley, 1997; see also Fahie \& Symons, 2003; Kerns, McInerney, \& Wilde, 2001; Pennington \& Ozonoff, 1996; Sonuga-Barke, Dalen, Daley, \& Remington, 2002). Some impairments are evident at the most basic levels of behaviour management, such as difficulty with self-control of actions and verbalisation, and may manifest as hyperactivity or extreme impulsivity in the early school years. More subtle impairments of executive functions that can impact organising and planning ability are often not developed until later in childhood (Barkley, 2003; Brown, 2002).

In contrast, the predominately inattentive type of ADHD is comprised of qualitatively different behavioural patterns, including difficulty in sustaining attention to prolonged activities, and distractibility (Milich, Ballentine, \& Lynam, 2001). It has been suggested that inattention may stem from an inability to hold mental representations active and use them to guide behaviour, a skill associated with working memory (Barkley, 1997).

Although working memory deficits in particular have often been claimed to be characteristic of at least some children with disorders of attention, there is in fact little evidence that they under-perform on classic measures of working memory such as reading and listening span (e.g., Adams \& Snowling, 2001; Kerns et al., 2001; Shue \& Douglas, 1992; Ruckridge \& Tannock, 2002; Sonuga-Barke et al., 2002). In line with this, Pennington and Ozonoff (1996) reported no evidence of general working memory (central executive) deficits in their influential review of the area. Further, studies on the effect of medication (methylphenidate) on performance in measures of working memory and executive function indicate an improvement in executive function tasks, but not in verbal working memory tasks (Mehta, Goodyer, \& Sahakian, 2004). One exception to these findings is children with both attentional disorders and reading difficulties, who do show some evidence of working memory deficits (Roodenrys, Koloski, \& 
Grainger, 2001). These deficits appear to relate to the co-morbid reading difficulties rather than the attentional problems per se.

It should, however, be noted that the majority of research in this area has focused on clinical groups exhibiting hyperactive behaviours. An unresolved issue relates to children with inattentive profiles and whether the impairment of working memory function results from a primary deficit in working memory or in intermittent failures to attend to working memory tasks. The classroom behaviour that we have observed to characterise children with working memory deficits - of normal social skills combined with extreme reservation in group activities and frequent failures to complete learning activities (Gathercole et al., in press) - certainly shares some features with that of inattentive children.

On balance, then, there is not a strong case for claiming that impairments of working memory are a general characteristic of children with attentional disorders. In children with hyperactive profiles of behaviour, working memory function is not unexpectedly poor. It does, however, remain possible that children with attentional problems that are of an inattentive nature may have impairments of working memory. If such impairments are diagnosed, remedial support following the principles outlined in the section below is recommended.

\section{Remedial support}

As impairments of both short-term and working memory are strongly associated with deficits in learning, effective remedial support is a priority irrespective of specific aetiology. The sections below provide some recommendations for useful elements of remediation and learning support programmes for affected children.

\section{Verbal short-term memory}

Attempts to boost directly verbal short-term memory skills typically target the rehearsal process that maintains representations in verbal short-term memory. Rehearsal can be trained in non-rehearsing children. This is achieved by providing initial practice in overt rehearsal, with the child saying aloud items to be remembered between presentations of successive items. A key element of this strategy is to encourage the child to rehearse cumulatively, by vocalising all of the words presented so far that have to be remembered rather than simply repeating the word that has just been presented. Once the child is able to use this strategy effectively, he or she is encouraged to use the same approach covertly, using silent rehearsal. This rehearsal training approach is effective in inducing rehearsal and memory gains both in typically developing groups of young children (Johnston, Johnson \& Gray, 1987) and in individuals with Down syndrome (Broadley \& MacDonald, 1993; Comblain, 1996; Laws et al., 1996).

Gains in verbal short-term memory scores are, however, relatively modest following rehearsal training, and in some cases have been found not to persist long after training. For this reason, it may be useful to complement direct training of verbal shortterm memory with a learning support programme that targets directly the process of vocabulary acquisition that is impaired in children with shortterm memory deficits. Vocabulary training could usefully take the form of multiple exposures to key new words presented in varying contexts, in which the child is provided with abundant opportunities to practise the immediate repetition as well as delayed recall and recognition of the novel sound structures. To ensure effective learning, new words should be represented and memory for them tested at increasing intervals of days and subsequently weeks, to optimise the process of consolidation of learning.

\section{Working memory}

Impairments of working memory result in several characteristic kinds of classroom failures. The examples below are taken from our observational study of three 5- and 6-year-old children with very poor working memory function (Gathercole et al., in press). The children's names are pseudonyms.

Forgetting instructions. All three children frequently failed to follow instructions from the teacher. The failure appeared to be due to forgetting the content of the instruction, particularly when it was fairly lengthy and did not represent a routine classroom activity. Here are three examples of this kind of failure.

On one occasion, the teacher gave the following instruction to David: 'Put your sheets on the green table, put your arrow cards in the packet, put your pencil away and come and sit on the carpet.' David failed to put his sheet on the green table. Teacher asked David if he could remember where he was supposed to put it; he couldn't, and needed reminding.

A second example involved Joshua. His teacher handed him his computer login cards and told to go and work on computer number 13. He failed to do this, because he had forgotten what computer he had been told to use.

Finally, Philip was asked to go back and put an $n$ in the word bean. He went back and asked the classroom assistant what he had been asked to do.

Place-keeping errors in complex tasks. Many examples of the child failing to keep track of position in complex tasks such as writing were observed. David's teacher decided that the children should write He had 36 barrels of gunpowder. The sentence was repeated until the children appeared to 
remember it. David successfully wrote he and had, and then could not remember what to write next. The teacher asked him to read what he had already written and then to say what word came next, but he could not. The teacher reminded him of the sentence. David then got stuck after writing several letters of the word gunpowder, attempted and failed to get the teacher's attention to help him, and then forgot that the word needed completing.

A further example of a place-keeping error was provided by Philip. The teacher wrote on the board Monday 11th November and, underneath, The Market, which was the title of the piece of work. Philip lost his place in the laborious attempt to copy the words down letter by letter, writing moNemarket. It appeared that he begun to write the date, forgot what he was doing and began writing the title instead.

Failure to meet simultaneous processing and storage demands. All three children frequently struggled in structured activities whose successful completion involved engaging in a relatively demanding processing activity at the same time as storage of information. Many of these activities involved counting. Although all three children were capable of counting accurately in the context of a simple task, many classroom activities combined counting with other cognitive processes. One frequent activity in literacy sessions involved counting the numbers of words in a sentence, often prior to writing the sentence down. Joshua was unable to recall the sentence, isolate each word and count it without assistance from the teacher. A group activity in Philip's class was to count the number of sentences in a text. Philip was unable to keep track of the tally number while reading aloud the text. In both cases, the task failure appeared to result from combining the memory demands of counting (keeping track of the tally number) in the context of a concurrent and fairly demanding processing activity.

Further failures were observed in activities that involved the detection of target items in spoken or written text. These tasks imposed significant processing demands (analysis and comprehension of spoken language, or text reading) in conjunction with the storage of multiple items. For example, the children in Joshua's class were asked to identify the rhyming words in a text read aloud by the teacher. They had to wait until all four lines had been read before telling the teacher the two words that rhymed: tie and fly. This task involves matching the sound structures of a pair of words, and storing them. Joshua was unable to do this.

\section{Learning support for children with working memory impairments}

There are two principal approaches to alleviating the learning difficulties that result from impairments of working memory. The first involves attempting to remediate working memory directly. As yet there is no accepted method of doing this, although some studies have boosted children's performance on working memory tasks by training the children in the use of rehearsal (Turley-Ames \& Whitfield, 2003), using the approach described in the previous section. What is not known is the extent to which children will spontaneously apply rehearsal strategies in the wide range of everyday contexts including classroom learning activities in which working memory demands are significant, and so whether the training will result in measurable learning benefits for the child.

An alternative approach to enhancing learning in children with impairments of working memory, and the one recommended here, is to minimise the memory-related failures in classroom-based learning activities frequently experienced by such children, via effective management of working memory loads (Gathercole \& Alloway, 2004). We are currently planning a controlled intervention study that adopts this approach, adopting the principles outlined below and summarised in Table 2. Further information regarding the intervention is provided at http://psychology.dur.ac.uk/research/wm/ WM\&learning.htm.

First, it is important to ensure that the child can remember what he or she is doing. On many occasions, we have observed children with low working memory simply forgetting what they had to do next, leading to failure to complete many learning activities (Gathercole et al., in press). Children's memory

Table 2 Working memory demands in classroom activities: some problems and solutions

\begin{tabular}{|c|c|}
\hline Problem & Solutions \\
\hline Child forgets the task & $\begin{array}{l}\text { - Give brief and simple instructions, broken down into separate steps if } \\
\text { task is very complex. } \\
\text { - Check the child can remember the instructions. Repeat instructions if } \\
\text { necessary. }\end{array}$ \\
\hline $\begin{array}{l}\text { Child cannot meet combined processing } \\
\text { and storage demands of activities }\end{array}$ & $\begin{array}{l}\text { - For activities involving sentences, reduce sentence length, reduce syntactic } \\
\text { complexity (simple active sentence forms are the easiest), and/or increase } \\
\text { familiarity of the vocabulary. }\end{array}$ \\
\hline Child loses place in a complex task & $\begin{array}{l}\text { - Use external memory aids such as number lines and useful spellings. } \\
\text { - Ensure that the child has plenty of practice in the use of the aids prior to } \\
\text { using them in more complex task settings. } \\
\text { - Find ways of marking for the child their progress in a complex task structure. }\end{array}$ \\
\hline
\end{tabular}


for instructions will be improved by using instructions that are as brief and simple as possible. Instructions should be broken down into parts where possible. One effective strategy for improving the child's memory for the task is frequent repetition of instructions. For tasks that take place over an extended period of time, reminding the child of crucial information for that particular phase of the task rather than repetition of the original instruction is likely to be most useful. Finally, one of the best ways to ensure that the child has not forgotten crucial information is to ask them to repeat it back.

Second, in activities that require the child to both process and store information, working memory demands and hence task failures will be reduced if the processing demands are decreased. For example, sentence writing was a source of particular difficulty for all of the children with low working memory that we observed. Sentence processing difficulty can be lessened by reducing the linguistic complexity of the sentence. This can be achieved in a variety of ways, such as simplifying the vocabulary, and using common rather than more unusual words. In addition, the syntax of the sentence can be simplified, by encouraging the child to use simple structures such as active subject-verb-object constructions rather than sentences with a complex clausal structure. The sentences can also be reduced in length. A child with poor working memory skills working with short sentences, relatively unfamiliar words and easy syntactic forms is much more likely to hold in working memory the sentence form and to succeed in a reasonable attempt at writing the sentence.

Third, the problem of the child losing his or her place in a complex activity can be reduced by breaking down the tasks into separate steps, and by providing memory support. External memory aids such as useful spellings displayed on the teacher's board or the classroom walls and number lines are widely used in classrooms. In our observational study, however, we found that children with poor working memory function often chose not to use such devices, but gravitated instead towards lowerlevel strategies with lower processing requirements and reduced general efficiency. In order to encourage children's use of memory aids, it may be necessary to give the child regular periods of practice in the use of the aids in the context of simple activities with few working memory demands.

Difficulties in keeping place in complex task structures may also be eased by increasing access to useful spellings which will also help prevent them losing their place in writing activities. Reducing the processing load and opportunity for error in spelling individual words will increase the child's success in completing the sentence as a whole. However, reading off information from spellings of key words on the teacher's board was itself observed to be a source of error in low memory children in our study, with children commonly losing their place within the word. Making available spellings of key words on the child's own desk rather than a distant class board may reduce these errors by making the task of locating key information easier and reducing opportunities for distraction. It may also be beneficial to develop ways of marking the child's place in word spellings as a means of reducing place-keeping errors during copying.

A final recommendation for improving the learning successes of individuals with poor working memory skills is to develop in the children effective strategies for coping with situations in which they experience working memory failures. Strategies may include encouraging the child to ask for forgotten information where necessary, training in the use of memory aids, and encouragement to continue with complex tasks rather than abandoning them even if some of the steps are not completed due to memory failure. The use of nonverbal cues and memory aids such as pictures and visual schematics may be of particular value here. We suggest that arming the child with such self-help strategies will promote their development as independent learners able to identify and support their own learning needs.

\section{Conclusions}

Impairments of working memory and of verbal shortterm memory are associated with a variety of neurodevelopmental disorders. In order to minimise the adverse consequences for learning and educational progress that result from these impairments, early diagnosis followed by remedial support that targets relevant domains of learning is strongly recommended.

\section{Acknowledgments}

The preparation of this article was supported by a project grant awarded by the Medical Research Council to S.E. Gathercole, A.M. Adams, and C.S. Willis. The authors wish to thank J. Elliott and P. Tymms for their useful feedback on earlier drafts of this manuscript.

\section{Correspondence to}

Susan E. Gathercole, Department of Psychology, University of Durham, Science Laboratories, South Road, Durham DH1 3LE, UK; Tel: 0191 3343255; Email: s.e.gathercole@durham.ac.uk

\section{References}

Adams, J.W., \& Snowling, M.J. (2001). Executive function and reading impairments in children reported by their teachers as 'hyperactive'. British Journal of Developmental Psychology, 19, 293-306. 
Alloway, T.P., Gathercole, S.E., Adams, A.M., \& Willis, C. (in press). Working memory and other cognitive skills as predictors of progress towards early learning goals at school entry. British Journal of Developmental Psychology.

Alloway, T.P., Gathercole, S.E., \& Pickering, S.J. (2004). Automated Working Memory Assessment. Computerised test battery.

Archibald, L.M.D., \& Gathercole, S.E. (2004). Shortterm memory, working memory and phonological awareness in Specific Language Impairment. Manuscript submitted for publication.

Baddeley, A.D. (1986). Working memory. Oxford: Oxford University Press.

Baddeley, A.D. (1996). Exploring the central executive. Quarterly Journal of Experimental Psychology, 49A, 5-28.

Baddeley, A.D. (2000). The episodic buffer: A new component of working memory? Trends in Cognitive Sciences, 4, 417-423.

Baddeley, A.D., Gathercole, S.E., \& Papagno, C. (1998). The phonological loop as a language learning device. Psychological Review, 105, 158-173.

Baddeley, A.D., \& Hitch, G. (1974). Working memory. In G. Bower (Ed.), The psychology of learning and motivation (vol. 8, pp. 47-90). New York: Academic Press.

Baddeley, A.D., \& Logie, R.H. (1999). The multiplecomponent model. In A. Miyake \& P. Shah (Eds.), Models of working memory: Mechanisms of active maintenance and executive control. New York: Cambridge University Press.

Barkley, R.A. (1997). ADHD and the nature of selfcontrol. New York: Guilford.

Barkley, R.A. (2003). Issues in the diagnosis of attention-deficit/hyperactivity disorder in children. Brain and Development, 25, 77-83.

Barrouillet, P., Bernardin, S., \& Camos, V. (2004). Time constraints and resource sharing in adults' working memory spans. Journal of Experimental Psychology: General, 113, 83-100.

Bellugi, U., Wang, P.P., \& Jernigan, T.L. (1994). Williams syndrome: An unusual neuropsychological profile. In S. Brodman \& J. Grafman (Eds.), Cognitive deficits in developmental disorders: Implications for brain function (pp. 23-56). Hillsdale NJ: LEA.

Bishop, D.V.M., Bishop, S., Bright, P., James, C., Delaney, T., \& Tallal, P. (1999). Different origin of auditory and phonological processing problems in children with language impairment: Evidence from a twin study. Journal of Speech, Language and Hearing Research, 42, 155-168.

Bishop, D.V.M., North, T., \& Donlan, C. (1996). Nonword repetition as a phenotypic marker for inherited language impairment: Evidence from a twin study. Journal of Child Psychology and Psychiatry, 37, 391404.

Briscoe, J., Bishop, D.V.M., \& Norbury, C.F. (2001). Phonological processing, language, and literacy: A comparison of children with mild-to-moderate sensorineural hearing loss and those with specific language impairment. Journal of Child Psychology and Psychiatry, 42, 329-340.

Broadley, I., \& MacDonald, J. (1993). Teaching shortterm memory skills to children with Down's syn- drome. Down's Syndrome: Theory and Practice, 1, 5662.

Broadley, I., MacDonald, J., \& Buckley, S. (1995). Working memory in children with Down's syndrome. Down's Syndrome: Research and Practice, 3, 3-8.

Brown, T.E. (2002). DSM-IV: ADHD and executive function impairment. In Proceedings of the Annual Meeting of the American Psychiatric Association, 2, 910-914.

Bull, R., \& Scerif, G. (2001). Executive functioning as a predictor of children's mathematics ability: Inhibition, task switching, and working memory. Developmental Neuropsychology, 19, 273-293.

Cain, K., Oakhill, J., \& Bryant, P. (2004). Children's reading comprehension ability: Concurrent prediction by working memory, verbal ability, and component skills. Journal of Educational Psychology, 96, 31-42.

Campbell, T., Dollaghan, C., Needleman, H., \& Janosky, J. (1997). Reducing bias in language assessment: Processing-dependent measures. Journal of Speech, Language and Hearing Research, 40, 519525.

Case, R., Kurland, D.M., \& Goldberg, J. (1982). Operational efficiency and the growth of short-term memory span. Journal of Experimental Child Psychology, 33, 386-404.

Catts, H.W., Fey, M.E., Tomblin, J.B., \& Zhang, Z. (2002). A longitudinal investigation of reading outcomes in children with language impairments. Journal of Speech, Language and Hearing Research, 45, 1142-1157.

Comblain, A. (1996). Auditory-vocal short-term memory functioning in Down's syndrome: Implication for the model of working memory. Approche Neuropsychologique des Apprentissages Chez l'Enfant, 8, 137-147.

Cowan, N. (2001). The magical number 4 in short-term memory: A reconsideration of mental storage capacity. Behavioral and Brain Sciences, 24, 87.

Daneman, M., \& Carpenter, P.A. (1980). Individual differences in working memory and reading. Journal of Verbal learning and Verbal Behavior, 19, 450-466.

Daneman, M., \& Merikle, P.M. (1996). Working memory and language comprehension: A meta-analysis. Psychonomic Bulletin and Review, 3, 422-433.

De Jong, P.F. (1998). Working memory deficits of reading disabled children. Journal of Experimental Child Psychology, 70, 75-96.

Dollaghan, C., \& Campbell, T.F. (1998). Nonword repetition and language impairment. Journal of Speech, Language and Hearing Research, 41, 1136-1146.

Edwards, J., \& Lahey, M. (1998). Nonword repetitions of children with specific language impairment: Exploration of some explanations for their inaccuracies. Applied Psycholinguistics, 19, 279-309.

Ellis Weismer, S., Evans, J., \& Hesketh, L. (1999). An examination of verbal working memory capacity in children with specific language impairment. Journal of Speech, Language and Hearing Research, 42, 1249-1260.

Ellis Weismer, S., Tomblin, J.B., Zhang, X., Buckwalter, P., Chynoweth, J.G., \& Jones, M. (2000). Nonword repetition performance in school-age children with and without language impairment. Journal of Speech, Language and Hearing Research, 43, 865-868. 
Elliot, C.D., Smith, P., \& McUlloch, K. (1996). British Ability Scales II. Windsor: NFER-Nelson.

Engle, R.W., Kane, M.J., \& Tuholski, S.W. (1999). Individual differences in working memory capacity and what they tell us about controlled attention, general fluid intelligence, and functions of the prefrontal cortex. In A. Miyake \& P. Shah (Eds.), Models of working memory: Mechanisms of active maintenance and executive control (pp. 102-134). New York: Cambridge University Press.

Fahie, C.M., \& Symons, D.K. (2003). Executive functioning and theory of mind in children clinically referred for attention and behavior problems. Journal of Applied Developmental Psychology, 24, 51-73.

Farran, E.K., Jarrold, C., \& Gathercole, S.E. (2001). Block design performance in Williams syndrome phenotype: A problem with mental imagery? Journal of Child Psychology and Psychiatry, 42, 719-728.

Fazio, B.B. (1996). Mathematical abilities of children with specific language impairment: A 2-year follow up. Journal of Speech, Language and Hearing Research, 39, 839-849.

Gathercole, S.E. (2004). Working memory and learning during the school years. Proceedings of the British Academy, 125, 365-380.

Gathercole, S.E., \& Alloway, T.P. (2004). Working memory and classroom learning. Professional Association for Teachers of Students with Specific Learning Difficulties, 17, 2-12.

Gathercole, S.E., Alloway, T.P., Willis, C., \& Adams, A.M. (2004a). Working memory in children with literacy and mathematical difficulties. Manuscript submitted for publication.

Gathercole, S.E., \& Baddeley, A.D. (1990). The role of phonological memory in vocabulary acquisition: A study of young children learning new names. British Journal of Psychology, 81, 439-454.

Gathercole, S.E., \& Baddeley, A.D. (1996). The Children's Test of Nonword Repetition. Psychological Corporation: London, UK.

Gathercole, S.E., Brown, L., \& Pickering, S.J. (2003). Working memory assessments at school entry as longitudinal predictors of National Curriculum attainment levels. Educational and Child Psychology, 20, 109-122.

Gathercole, S.E., \& Hitch, G.J. (1993). The development of rehearsal: A revised working memory perspective. In A. Collins, S.E. Gathercole, M.A. Conway, \& P.E. Morris (Eds.), Theories of memory. Hove: Lawrence Erlbaum Associates.

Gathercole, S.E., Hitch, G.J., Service, E., \& Martin, A.J. (1997). Short-term memory and long-term learning in children. Developmental Psychology, 33, 966-979.

Gathercole, S.E., Lamont, E., \& Alloway, T.P. (in press). Working memory in the classroom. In S. Pickering (Ed.), Working memory and education. Elsevier Press.

Gathercole, S.E., \& Pickering, S.J. (2000). Working memory deficits in children with low achievements in the national curriculum at seven years of age. British Journal of Educational Psychology, 70, 177-194.

Gathercole, S.E., \& Pickering, S.J. (2001). Working memory deficits in children with special educational needs. British Journal of Special Education, 28, 8997.
Gathercole, S.E., Pickering, S.J., Knight, C., \& Stegmann, Z. (2004b). Working memory skills and educational attainment: Evidence from National Curriculum assessments at 7 and 14 years of age. Applied Cognitive Psychology, 40, 1-16.

Geary, D.C., Hoard, M.K., Byrd-Craven, J., \& DeSoto, M.C. (2004). Strategy choices in simple and complex addition: Contributions of working memory and counting knowledge for children with mathematical disability. Journal of Experimental Child Psychology, 88, 121-151.

Geurts, H.M., Vertie, S., Oosterlaan, J., Roeyers, H., \& Sergeant, J.A. (2004). How specific are executive functioning deficits in attention deficit hyperactivity disorder and autism? Journal of Child Psychology and Psychiatry, 45, 836-854.

Goldman, R., \& Fristoe, M. (2000). Gordman Fristoe 2: Test of articulation. American Guidance Service, Inc., Minnesota.

Hanley, J.R., Young, A.W., \& Pearson, N.A. (1991). Impairment of the visuo-spatial scratchpad. Quarterly Journal of Experimental Psychology, 43, 101126.

Hinshaw, P. (1994). Attention deficits and hyperactivity in children. London: Sage Publications.

Jarrold, C., Baddeley, A.D., \& Hewes, A.K. (1999). Genetically dissociated components of working memory: Evidence from Down's and William's syndrome. Neuropsychologia, 37, 637-651.

Jarrold, C., Baddeley, A.D., \& Hewes, A.K. (2000). Verbal short-term memory deficits in Down's syndrome: A consequence of problems in rehearsal? Journal of Child Psychology and Psychiatry, 41, 233-244.

Jarrold, C., Baddeley, A.D., Hewes, A.K., \& Phillips, C. (2001). A longitudinal assessment of diverging verbal and non-verbal abilities in the Williams syndrome phenotype. Cortex, 37, 423-431.

Jarrold, C., Baddeley, A.D., \& Phillips, C.E. (1999). Down's syndrome and the phonological loop: The evidence for, and importance of, a specific verbal short-term memory deficit. Down Syndrome: Research and Practice, 6, 61-75.

Jarvis, H.L., \& Gathercole, S.E. (2003). Verbal and nonverbal working memory and achievements on national curriculum tests at 11 and 14 years of age. Educational and Child Psychology, 20, 123-140.

Johnston, R.S., Johnson, C., \& Gray, C. (1987). The emergence of word length effect in young children: The effects of overt and covert rehearsal. British Journal of Developmental Psychology, 5, 243-248.

Just, M.A., \& Carpenter, P.A. (1992). A capacity theory of comprehension: Individual differences in working memory. Psychological Review, 99, 122-149.

Kerns, K.A., McInerney, R.J., \& Wilde, N.J. (2001). Time reproduction, working memory, and behavioural inhibition in children with ADHD. Child Neuropsychology, 7, 21-31.

Laws, G. (1998). The use of nonword repetition as a test of phonological memory in children with Down syndrome. Journal of Child Psychology and Psychiatry, 39, 1119-1130.

Laws, G., MacDonald, J., \& Buckley, S. (1996). The effects of a short training in the use of a rehearsal strategy on memory for words and pictures in 
children with Down's syndrome. Down's Syndrome: Research and Practice, 4, 70-78.

Logie, R.H. (1995). Visuo-spatial working memory. Hove, Lawrence Erlbaum Associates.

Mackenzie, S., \& Hulme, C. (1987). Memory span development in Down's syndrome, severely subnormal and normal subjects. Cognitive Neuropsychology, 4, 303-319.

Mayringer, H., \& Wimmer, H. (2000). Pseudoname learning by German-speaking children with dyslexia: Evidence for a phonological learning deficit. Journal of Experimental Child Psychology, 75, 116-133.

Mehta, M.A., Goodyer, I.M., \& Sahakian, B.J. (2004). Methylphenidate improves working memory and setshifting in AD/HD: Relationships to baseline memory capacity. Journal of Child Psychology and Psychiatry, 45, 292-305.

Milich, R., Ballentine, A.C., \& Lynam, D. (2001). ADHD combined type and ADHD predominantly inattentive type are distinct and unrelated disorders. Clinical Psychology - Science and Practice, 8, 463-488.

Montgomery, J. (1995). Examination of phonological working memory in specifically language impaired children. Applied Psycholinguistics, 16, 355-378.

Montgomery, J. (2000). Verbal working memory and sentence comprehension in children with Specific Language Impairment. Journal of Speech, Language and Hearing Research, 43, 293-308.

Nation, K., Adams, J.W., Bowyer-Crane, C.A., \& Snowling, M.J. (1999). Journal of Experimental Child Psychology, 73, 139-158.

Pennington, B.F., \& Ozonoff, S. (1996). Executive functions and developmental psychopathology. Journal of Child Psychology and Psychiatry, 37, 51-87.

Pickering, S.J., \& Gathercole, S.E. (2001). Working Memory Test Battery for Children. Hove, UK: Psychological Corporation.

Pickering, S.J., \& Gathercole, S.E. (2004). Distinctive working memory profiles in children with special educational needs. Educational Psychology, 24, 393408.

Pickering, S.J., Gathercole, S.E., \& Peaker, S.M. (1998). Verbal and visuospatial short-term memory in children: Evidence for common and distinct mechanisms. Memory and Cognition, 26, 1117-1130.

Roodenrys, S., Koloski, N., \& Grainger, J. (2001). Working memory function in attention deficit hyperactivity disordered and reading disabled children. British Journal of Developmental Psychology, 19, 325-337.

Ruckridge, J.R., \& Tannock, R. (2002). Neuropsychological profiles of adolescents with ADHD: Effects of reading difficulties and gender. Journal of Child Psychology and Psychiatry, 43, 988-1003.

Seigneuric, A., Ehrlich, M.F., Oakhill, J.V., \& Yuill, N.M. (2000). Working memory resources and children's reading comprehension. Reading and Writing, 13, 81-103.
Service, E., \& Craik, F.I.M. (1993). Differences between younger and older adults in learning a foreign vocabulary. Journal of Memory and Language, 32, 608-623.

Service, E., \& Kohonen, V. (1995). Is the relation between phonological memory and foreign-language learning accounted for by vocabulary acquisition? Applied Psycholinguistics, 16, 155-172.

Shue, K.L., \& Douglas, V.I. (1992). ADHD and the frontal lobe syndrome. Brain and Cognition, 20, 104124.

Siegel, L.S., \& Ryan, E.B. (1989). The development of working memory in normally achieving and subtypes of learning disabled children. Child Development, 60, 973-980.

SLI Consortium. (2002). A genomewide scan identifies two novel loci involved in Specific Language Impairment. American Journal of Human Genetics, 70, 384398.

Sonuga-Barke, E.J.S., Dalen, L., Daley, D., \& Remington, B. (2002). Are planning, working memory, and inhibition associated with individual differences in preschool ADHD symptoms? Developmental Neuropsychology, 21, 255-272.

Swanson, H.L. (1993). Working memory in learningdisability subgroups. Journal of Experimental Child Psychology, 56, 87-114.

Swanson, H.L. (1994). Short-term memory and working memory - Do both contribute to our understanding of academic achievement in children and adults with learning disabilities? Journal of Learning Disabilities, 27, 34-50.

Tallal, P., Merzenich, M., Miller, S., \& Jenkins, W. (1998). Language learning impairment: Integrating research and remediation. Scandinavian Journal of Psychology, 39, 197-199.

Tomblin, J.B., Records, N.L., Buckwalter, P., Zhang, X., Smith, E., \& O'Brien, M. (1997). Prevalence of specific language impairment in kindergarten children. Journal of Speech, Language and Hearing Research, 40, 1245-1260.

Turley-Ames, K., \& Whitfield, M.M. (2003). Strategy training and working memory task performance. Journal of Memory and Language, 49, 446-468.

Turner, M.L., \& Engle, R.W. (1989). Is working memory capacity task dependent? Journal of Memory and Language, 28, 127-154.

Wang, P.P., \& Bellugi, U. (1994). Evidence from two genetic syndromes of a dissociation between verbal and visuo-spatial short-term memory. Journal of Clinical and Experimental Neuropsychology, 2, 317322.

Wechsler, D. (1992). Wechsler Intelligence Scale for Children-IV. San Antonio, TX: Psychological Corporation.

Manuscript accepted 1 December 2004 